\title{
Preliminary Kindergarten Outdoor Landscape Design
}

\author{
Xiangguo Ge \\ Jiangxi Institute of Fashion Technology \\ Nanchang, China 330201
}

\begin{abstract}
Scientific, reasonable and humanized kindergarten outdoor landscape design can give children positive and lively growing environment. It can improve children's interest, self-knowledge, also can establish a harmonious relationship with others, and promote children's physical and mental growth. Fully preparing kindergarten outdoor landscape design, formulating scientific and rational planning are the premise and foundation to ensure the quality of it.
\end{abstract}

Keywords-kindergarten; Landscape design; outdoor landscape

\section{INTRODUCTION}

A kindergarten is a school that the children are the first time to contact the education environment. The campus landscape is the important factor that can affect the development of preschool children psychology. Worm and Lewis think that all person experience the environment in a similar way. The reaction of environment can be carried out by social and cultural transmission. Kindergarten campus environment is an important place for children to obtain psychological experience. In order to make the positive leading to the development of children's psychology, campus need to highlight the cultural landscape design, which makes the education meaning of landscape environment more clear and the landscape form and content of moral education more fullness.

Kindergarten outdoor landscape is the main place to children's outdoor activities. It can ensure children's healthy development, broaden the children's interest vision, develop children's intelligence, let the children understand the nature, and played a key role to establish contact with nature. Since the 1960 's, western scholars have realized that a person's intelligence can be changed, especially in the first eight years. They said that intelligence developmental is related with cognitive learning. So based on the experience and the activity learning ways are very popular with the children.

However, driven by economic development, our country's kindergarten designs have the fixed style. It is lack of personality. The kindergarten outdoor environment has been ignored for a long time. Some kindergarten teachers take outdoors environment as a place that used to run. This kindergarten outdoor space environment consciously ignore will affect children's physical and mental development. Therefore, it is necessary to scientific analyze the children's educational environment and put forward a reasonable solution to promote early childhood education.

\section{THE PRESENT SitUATION OF OUR KINDERGARTEN OUTDOOR LANDSCAPE SPACE DESIGN}

Children's initial sensory and cognitive is through its own action and interaction of external things, and gradually built their environment cognitive structure. Since the 1970's, the Swiss children psychologist Piaget's theory has a great impact on China's preschool education. Piaget thinks that cognitive is not obtained from teachers' teaching, but learners obtained it through the interaction with the environment and interpersonal interaction in certain space environment.

So we can say, for the children any time the environmental education will affect the children directly, intuitively, imperceptibly. This kind of osmosis education will give other education methods some stress. Therefore, this kind of education way that the children are influenced by the environment are popular with the field of education and social. Kindergarten create interesting observation can strengthen children's perception of the environment. And it can enrich experience way of their environment. The shape, size, distance, azimuth, color of Kindergarten environment space will stimulate young children's visual, kinesthetic and tactile. Children gradually know the world in the complex perceptual activities.

For kindergarten environment landscape design, the concept of mostly stay in metope design and the children's outdoor play equipment put. It seems that the environmental design is depended by the designer's human imagination or the teacher of the art language. They think that the children will like it as long as the color is colorful and the composition is full. They will not consider that the surrounding environment influence is very important for the children. And they less make use of the surrounding environment as the influence of the characteristic factors of design elements. However, with the development of China's economy and the improvement of people understanding, many people realized that this neglect the natural environment, the single landscape design will be harm of the early childhood education,

In China childhood education career has made much progress since the 1980's. Many organizations help the kindergarten, mainly including government, charitable organizations, for-profit investors. The sponsor not only wants to improve the quality of teaching environment, but also increasing teachers' numbers. But a large number of kindergarten outdoor venue didn't pay attention by the sponsors. For example, narrow space, lacking of facilities, 
are still a weak in the outdoor landscape design. Many designers only used the old scheme, they didn't adjust the project design according to the local condition. At present, the prominent problems mainly displays in the following aspects:

\section{A. Games Form Is Single and Lack of Change}

Influenced by the mainstream game form, kindergarten outdoor facilities, such as seesaw, slide, swing become indispensable stylized equipment, even is the only game equipment. It is hard to find a game equipment has its local features. This unified equipment will inevitably lead to children education lack of characteristics.

\section{B. Single Vegetation}

Some kindergarten blindly seek outdoor landscape trees, they only plant evergreen tree. In order to pursuit a thriving illusion, some of the kindergarten moved a lot of resin. The environment of the "four spring-like" due to lack of natural ecological change and appear boring. And the natural education becomes the false appearance.

\section{Lack of Standardization and Pose a Safety Hazard}

Scientific and reasonable scale and facilities are the first condition to ensure the safety of infant movement. In order to save costs, some kindergartens make your own devices. Because lack professional try and possible create entities safety facilities. In order to save space some kindergarten set the sports facilities cluster together, during the children extracurricular activity time, it can easily lead to "manmachine collision".

\section{The Boundary Block Ignores Children Communicate with the Outside World}

For the children safety, some kindergarten do the thick walls around the yard, then it keep out the line of children sight to the outside world, and lock their heart of the communication with the outside world. In abroad, many kindergarten is equipped with safety sheet tower, standing on the tower top, the children can look far away from the kindergarten.We think it a good way to communicate with the outside world.

\section{CRITICIZE THE LANDSCAPE DESIGN OF KINDERGARTEN}

Children aged 3 to 5 physiological development characteristic main display such as sight, hearing, smell, skin sensation system development. At the same time, as the children expand the natural and interpersonal scope, their psychological also will change. This determines the designers only pay attention to the body of the preschool children characteristics is not enough. Relative to the human body measurement scale, focusing on children's physical development and psychological development is also crucial. Outdoor space landscape designs become affect children's development key factors about height, physiological and psychological. But children have no clear judgment about the environment, and they don't know how to express their feelings about the environment, so the designer is hard to get effective design basis from the children. Some studies have shown that most adults memories of childhood are rich, and there are a lot of people can be traced back to before the language expression. So, primary school students, adults' memory, kindergarten teachers, children development experts and psychologist suggestion are the main way to provide the basis for design.

\section{A. Design Should Be Suitable for Purpose of Education}

Firstly, outdoor landscape design should be a part of the kindergarten education. The design should be closely around the teaching purpose. Such as teachers hope that in the teaching process teachers let the students participate the activities to exercise their attention and durability. it needs to build relatively independent games facilities like a swing, but the group participation games are not conducive to the realization of teaching goals.

\section{B. The Design Should Take Care of Children's Psychology, and Expand Social Skills}

Children at the age of 3 to 5 haven't formed stage social habits. So they will display they character by game .They changes their individual character in different situations. Though the same situation, they also appear different individual character. Constructing a tolerate setbacks private little space, creating a large space that is suitable for passion of exercise are helpful. In real life, many outdoor landscape design more biased towards large sports venue design, it will bruises the children social sense. The division of a variety of properties of space is one of the effective methods to relieve children tension. Most experts agree that the imitation of the real object will limit children's imagination. And too abstract modelling often make children struggling to identify and reduce their participation interest. Moderate imagination of design is also one of the most important aspects of the adjustment of children psychology. In addition, during their game process if the parents company them, they will relax and enhance self-confidence. So the designer should consider adding some adult game facilities in the kindergarten outdoor will be beneficial the children growth.

\section{The Design Should Follow the Characteristics of Children's Physical Growth.}

Swiss, the Children Psychologist. Piaget, Jean Piaget's Theory of Cognitive Development showed that children experience of mathematical logic depends on their practice and discovery. Establish the changeable sensory stimulation environment is one of the elements of ascending children wisdom. To establish relatively reasonable appraisal target coordinates can make kindergarten landscape design safety.

\section{CONCLUSION}

Completes the kindergarten outdoor landscape design, and promote the role of children' development, just need to understand the characteristics of the preschool children's psychological development. On the basis of full recognition general environment material may contain that we should 
know value that promote the development of children, and use scientific methods to design the environmental materials and guarantee children living in the campus environment. Let the children can share a lively, healthy living and learning environment.

Children between the ages of four to six gradually has a spatial cognition ability. Therefore, we should pay attention to develop the children space cognitive ability when the designers design the landscape of the kindergarten outdoor. For example, we can arouse the children's through places wall, sculpture, such as landscape design, interesting and promote the development of its spatial cognition that can make the students initiatively explore space by embedding all sorts of three-dimensional design of the landscape in metope design. So the three-dimensional space and cognition can be expressed by these elements. A single, Pure, lively natural color is given priority to others when we consider the landscape color design. Because children are easy to understand and resonate. Lively colour can make them have a clearly the rhythm feeling, and it is benefit for them to promote the development of its colors cognition. When we have a design, we should take into account the preschool children's cognitive level. Let the environment culture elements, such as shapes and colors, induced the children's learning interesting. Although the preschool children have been able to read, but their reading book is not the words, and at first they contact the vivid pictures. And all kinds of vivid images of cultural landscape design can promote children's language development. Design must also take care of the children's social development, for example, through the special design of toilet environment, such as the colour of the men's room is bright and modeling is integrity, frank. But the girl's toilet environment design, we should consider the color is light, soft and sleek. It can fully embody the character of sex. Everyday when the children contact, see and feel it, it will have an important positive role in helping them to promote the social development.

Attention and constantly development the kindergarten outdoor landscape design must have a long-term experience and scientific forecast accumulation. Preschool education is a long-term and complicated process. Systematic and scientific improving the quality of kindergarten outdoor landscape design is to ensure the healthy development of children's subjectivity and individuality.

\section{REFERENCES}

[1] Hai-feng li yun-xia dong. Property about the style of the Tuscan landscape analyses [J]. Journal of generation of gardening, 2011, (9).

[2] Zhu yong, walk close to the ideal teaching education [M]. Guangxi Lin: lijiang publishing club, 2007.

[3] Mint. Light and shadow game: Wyne sales offices in Bangkok, Thailand [J]. Journal of interior design and decoration, 2011, (4).

[4] LingZi, yan. Floating city A real estate sales center in xiamen [J]. Journal of interior design and decoration, 2011, (3).

[5] Yang li, li-jiao yan, xiao-chun jin. Introduction to sales offices landscape design: the elegant dynasty floor landscape design as an example to hangzhou [J]. Journal of art and design: theory, 2011, (2). 